\title{
News criteria on social media Comparing news media use of Facebook and Twitter ${ }^{1}$
}

\author{
BY JAKOB LINAA JENSEN
}

\section{Introduction}

The supply of news is larger than ever. However, traditional mass media are no longer in a privileged position as the exclusive gatekeepers of news; they face competition from alternative media, organizations and citizens who can produce and distribute news instantly through websites, blogs and social media. Furthermore, a significant share of news consumption is now based on links and stories appearing in users' social media newsfeed. Every week, 56 percent of Danish citizens get news through social media that have become a major battleground for attention, clicks, viewers and readers (Schrøder et al. 2018). If traditional media are to retain attention and audience they have to play by social media logics.

This article identifies and compares news criteria of social media posts shared on 25 Danish Twitter accounts and 25 Danish Facebook pages, representing exactly the same 25 news media actors. Hereby I investigate the criteria by which media frame their stories shared through social media and compare different uses and strategies on Facebook and Twitter.

\section{The outline}

In the following, I will start by discussing the concepts of news values and news criteria. Next, I will address existing studies on 
news criteria in general and of social media in particular. In the methods section I will establish a framework for comparing news criteria of posts shared by Danish news media through Facebook and Twitter. The analysis starts by a quantitative analysis of the Twitter accounts and Facebook pages: how much do the different media outlets post on the respective platforms? The second part of the analysis focuses on news criteria identified in media posts on the two platforms. Finally, I will reflect on similarities and differences and relate them to current debates on social media and journalism.

\section{News criteria of traditional and social media}

Every day, when journalists choose what to write, publish or broadcast they can select from an almost infinite number of topics and events. News production takes place in a social context and journalists and editors are bound by certain social and cultural constraints in their news selection and production (Schudson 1989). The mechanisms by which topics, problems and events become news have been described by concepts like newsworthiness (Epstein 1973) and news values (Gans 1979). The concept newsworthiness is often associated with Galtung \& Ruge (1965) and their study of news coverage of three international conflicts in four Norwegian newspapers.

Despite the works' classical status in news research, it has been criticized on several points: Hjarvard (1995) points out that the work is too focused on distinct events and their ability to become news whereas most potential news stories are harder to delimit and define. Furthermore, Harcup \& o'Neill (2001) revisit the original work by Galtung \& Ruge and criticize that it addresses only newspapers and that their focus on foreign policy conflicts is too narrow to establish general news criteria. Studying the news in three major national newspapers in the UK they refine and develop the news criteria for a more contemporary context. Among the new conclusions, they identify the rise of celebrity and entertainment as independent news values.

As Ryan (1991) says, there is no final definition of news criteria. Rather, they are analytical tools, used by researchers to describe 
how issues become news. As analytical tools news criteria might become self-fulfilling prophecies as journalists and editors study them and incorporate the ideas in their editorial processes. An example is the five criteria (timeliness, sensation, importance, identification and conflict) that were defined in a Danish context by Asmussen \& Meilby (1977) and Kramhøft (2000). Based on a reading of international research they are a kind of a "cookbook" for journalists and have been taught to Danish journalism students for decades. Furthermore, they have a dominant position in Danish news and journalism and have been employed in earlier research, making them a useful backbone for the present analysis. For instance, Schultz (2007) has tested the criteria in an ethnographic study of TV news by Danish broadcaster DR. She identifies the five criteria as still relevant but adds three more: good pictures, simplicity and liveness (ibid. p. 63). Also, she identifies a dominant news value of exclusivity: TV wants to be first (and alone) with the stories. Taking the analysis further to netbased news, Hartley (2013) in an ethnographic study of 35 Danish online journalists also finds exclusivity to be of paramount importance in a net-based world.

Recently, some scholarly focus has turned to news criteria of stories disseminated through social media. Theoretically, Rainie \& Wellman (2014:214) claim that stories spread through social media might be framed differently than stories in traditional media. Emotions and sensations rather than facts dominate because social media have "different subjects, different narrative sensibility and different pathways to capture the attention" (ibid.). Furthermore, when news selection and reading are increasingly based on popularity, "likes" and "shares" rather than traditional editorial filters, the spectacular, the entertaining, the personal or the conflicting might come to dominate the news cycle (Meyer et al. 2010).

Empirical studies of social media sharing patterns among users support such hypotheses. Boczkowski \& Mitchelstein (2012) demonstrate that controversial news with a conflict frame is likely to be the most shared during election times. Hamdy \& Gomaa (2012) in their study of the role of social media in the Egyptian uprising in 2011 find that identification, or what they call "the human interest frame", is dominant. 
Traditional media have actively tried to adjust to the new social media circumstances. For almost a decade, media companies have employed social media editors, not only for sourcing news from social media (Gleason 2010) but more importantly for using social media as an alternative distribution channel (Kalsnes \& Larsson 2017). These social media editors have often been accused of being too focused on likes and shares rather than journalistic content. For instance, Hille \& Bakker (2013) have shown that Dutch media do not seem to have a journalistic strategy for dissemination through social media. Rather, their practice is based on 'audience distribution'. Other studies have demonstrated how celebrity (Ekman \& Widholm 2014) and sensationalism (Kilgo et al. 2016; Highfield 2017) become dominant features of news stories shared through social media. Harcup \& o'Neill (2016) in a follow-up of their earlier study update the news criteria, including electronic as well as social media, and add exclusivity, conflict, drama, audiovisuals and "shareability" as news criteria. They find that bad news, surprise and entertainment are the most identified criteria in electronic media.

There are only a few studies specifically comparing Facebook and Twitter even though one might expect different patterns and strategies for news sharing as the two platforms differ in architecture, purpose and user demography (Bossetta et al. 2017). Among existing works, Larsson \& Christensen (2017) in a study on Swedish Television's use of social media during a national election find that Twitter is used more extensively and in a more interactive fashion than Facebook, like a second screen. Anderson and Caumont (2014) find that contrary to Facebook, Twitter is widely used for "breaking news". Kalsnes \& Larsson (2017) in a Norwegian study find that news sharing through Twitter tends to be dominated by social "hard news" like economy, national and foreign policy whereas Facebook is more focused on "soft news", for instance sports, gossip and entertainment.

However, none of these interesting studies focus specifically on the possible difference in news criteria used on Facebook and Twitter, respectively. This article aims at filling that research gap, using Danish news media as a case. The specific method will be described below. 


\section{Methodology}

As mentioned, the aim of the study is to compare news criteria identified in social media posts shared by Danish media on Facebook and Twitter. Sometimes, the posts are unique stories, but most often, as we shall see, the media use Facebook and Twitter to link to existing stories on their web sites or elsewhere. No matter what, the focus here is on news criteria employed in the social media posts rather than in the linked stories. The main target is to identify differences between Facebook and Twitter although social media criteria are also discussed, compared to existing knowledge on news criteria.

As a methodological frame for the comparative approach I developed what I call the Danish Twitter News Index and the Danish Facebook News Index. The names and the research design are inspired by a similar project in Australia, ATNIX, the Australian Twitter News Index (see for instance Bruns et al. 2011). This project identifies the main media actors in the Australian Twittersphere and the kind of stories they share. Where the Australian project relied on URLs distributed through social media posts this project focuses on the content of tweets and Facebook posts. Even though most tweets and posts link to articles, photos or videos from the media's own websites, a number of stories have no links. Such stories are not included by the Australian approach which is also limited to Twitter only.

The Facebook and Twitter news indexes are developed based on identical methods and include the same media to allow for maximum comparison. The initial sample included all daily and some relevant weekly nationwide news media, written, visual or internet-based, covering relevant political and societal agendas. Media dedicated strictly or mainly to sports, lifestyle journalism, music and gossip were excluded. Some media, for instance the large public-service broadcasters DR and TV 2 and major newspapers have divided their social media presence into several pages or accounts, representing different TV channels or topic areas. Thus, the same medium, for instance DR, may have several Facebook pages and Twitter accounts included in the final sample that consisted of 51 Facebook pages and 49 Twitter accounts. 
Furthermore, for comparison purposes, Facebook pages should correspond to Twitter accounts, otherwise the account or page was excluded from the sample. Finally, if a page or account had no or very low activity, it was excluded. In the end, the sample consisted of 25 corresponding Twitter accounts and Facebook pages spanning across a period of three months, December 2014 - February 2015. The period was selected to avoid any major planned events like elections or referendums and to exclude the summer holiday.

The tweets were harvested by DMI TCAT, a tool developed by the Digital Methods Initiative at the University of Amsterdam (https://www.digitalmethods.net). The Facebook pages were harvested by Digital Footprints, developed by researchers at Aarhus University (www.digitalfootprints.dk).

The different nature and architecture of Twitter and Facebook is also apparent when it comes to data retrieval. Where it was straightforward to get all Facebook posts from the 25 media pages, it was a bit unclear what tweets to include. Being a study of media distribution rather than user sharing, user comments were not included in the Facebook sample.

One might argue that the analysis is skewed as the procedure includes a lot more tweets than Facebook posts, 70.045 tweets versus 15.999 posts. However, Twitter in Denmark is still small compared to Facebook: when including user interaction in the analysis, Facebook will generate much more activity. The 15.999 Facebook posts generated more than 2.000 .000 comments. The corresponding figure when including the Twitter equivalents, retweets and comments, is around 230.000. This is not surprising as Facebook has 3,5 million monthly users in Denmark, versus 457.000 on Twitter (https://www.socialemedier.dk/socialemedier-2016-i-danmark). However, I will still argue that my approach is the best possible solution for a comparison. The choice highlights that comparative analyses of different social media platforms often pose such challenges (Linaa Jensen 2017). I will return to the possible implications in the conclusion.

As the total number of tweets and posts is very high and in order to make similar samples, 3.000 tweets and 3.000 posts were selected, based on random sampling distributed with even numbers of tweets and posts from each of the three months. I ana- 
lyzed the tweets and posts as they appeared on the social media platforms. However, some posts and tweets appeared unclear or ambivalent and it was necessary to follow the link and read the main story, or to explore the context a bit further. Thus, even though the coding process focused on the manifest content on Facebook and Twitter, sometimes further information had to be included to allow for a consistent coding.

For the coding, I focused on the five news criteria discussed above: timeliness, sensation, importance, identification and conflict. The criteria have been taught to generations of Danish journalists and used as a framework in several qualitative studies, for instance Schultz (2006) as discussed above. However, I was surprised to learn that there have been no systematic, quantitative studies employing the criteria. Arguments might be that they are context dependent, difficult to code or broad and fluffy and unlikely to make sense. Therefore, it was an independent methodological challenge to apply them to a quantitative content analysis framework. As a student assistant was hired for the coding process it was necessary that both she and I had a profound and similar understanding of the meaning of the criteria. We understood them as follows, based on a reading of Asmussen and Meilby (1977) and Kramhøft (2000) and on the applied use by Schultz (2006):

Timeliness: We find that the story focuses on a contemporary topic taking place at the time of writing.

Sensation: We find that the story addresses something spectacular or surprising, something unexpected like "man bites dog" or "single mother wins in the lottery".

Importance: This is a problematic category as there may be different conceptions of importance for different journalists and audiences. By importance we mean that the story claims to be relevant, either to the intended reader or society in general. It can address central political issues, significant events or topics relevant in the daily lives of the audience.

Identification: We find that the story addresses the reader by a personal angle, either addressing him or her, or portraying someone they can identify with, a countryman or someone in a similar situation. For instance, it could be stories like "Are you ready to vote?" or "No Danes among the dead in China earthquake". 
Conflict: We find that the story highlights a conflict between people or institutions, addresses or frames a problem taking place right now or in the future, or in other ways portrays something that "ought to be solved". The criterion is typically found in coverage of controversial topics like immigration or crime or in political news using the horserace frame, for instance opposition vs government.

We coded the tweets and posts two times: First, we identified and coded every single news criterion we could identify. It could be from zero to all five. Next, we coded the "dominant" criterion, the most important one in the story. If there was any doubt about the latter, the story was not coded. The coding scheme is shown in table 1.

\begin{tabular}{|l|l|}
\hline \multirow{5}{*}{ News criterion } & Timeliness \\
\cline { 2 - 2 } & Sensation \\
\cline { 2 - 2 } & Relevance \\
\cline { 2 - 2 } & Identification \\
\cline { 2 - 2 } & Conflict \\
\hline \multirow{4}{*}{ Dominant news criterion } & Timeliness \\
\cline { 2 - 2 } & Sensation \\
\cline { 2 - 2 } & Relevance \\
\cline { 2 - 2 } & Identification \\
\cline { 2 - 2 } & Conflict \\
\hline
\end{tabular}

Table 1. Overview of codes in the content analysis.

Even though the research assistant ended up doing the entire coding, the author initially coded 300 stories as a pilot test, both to ensure validity of criteria and to establish inter-coder reliability. After two iterations, inter-coder reliability, measured by Krippendorf's Alpha, reached a level of 0,95 and was deemed satisfactory. Even though we are confident about the quality of the coding, one must remember that criteria are not objective features and must be seen as something identified by the researcher, based on the best possible understanding of the text. 


\section{The analysis part I - overall activity of Twitter and Facebook}

The analysis includes 25 Facebook pages and 25 Twitter accounts over three months, December 2014 - February 2015. Among the media included there are ten newspapers: three tabloid newspapers, four traditional broadsheets, one business paper and one Christian inspired paper. Finally, there is a small socialist paper published three times a week but with daily online editions. There are two weekly papers, both long-standing political magazines frequently quoted in other media, too. Six pages and accounts originate from TV stations, three from each of the public-service broadcasters, DR (paid through license fees) and TV 2 (paid through commercials). Some pages belong to an entire channel, some to a specific (relevant) program. Three accounts belong to radio stations, two to DR and one to the commercial public-service broadcaster Radio 24-7. Finally, some pages and accounts belong to various web media.

In table 2 (below) I summarize the activity of the 25 Twitter accounts and Facebook pages. They have been divided into different categories, making it possible to compare across electronic and written media and new and old media types. The table shows the respective media and media types and their share of all Facebook posts and tweets, respectively. In general, daily papers and web media are most active on Facebook whereas radio and TV media are most active on Twitter. Further details reveal differences within the media types. Among the daily newspapers, tabloids are more "Facebook media" than broadsheets. This may not come as a surprise since large tabloids like Ekstra Bladet and Facebook generate lively debates among Facebook followers and deliberately boost such debates.

\begin{tabular}{|l|l|l|}
\hline & Tweets & Facebook posts \\
\hline Daily papers & $\mathbf{3 1 . 4}$ & $\mathbf{5 3 . 4}$ \\
\hline Berlingske (broadsheet) & 0.3 & 8.0 \\
\hline BT (tabloid) & 7.8 & 8.9 \\
\hline Børsen (business broadsheet) & 0.6 & 2.0 \\
\hline Arbejderen (socialist niche paper) & 1.9 & .2 \\
\hline
\end{tabular}




\begin{tabular}{|l|l|l|}
\hline Information (broadsheet) & 0.4 & 1.7 \\
\hline Ekstra Bladet (tabloid) & 3.5 & 9.4 \\
\hline Jyllands-Posten (broadsheet) & 8.9 & 5.9 \\
\hline Kristeligt Dagblad (Christian broadsheet) & 1.5 & 3.0 \\
\hline Metroxpress (tabloid, free) & 1.5 & 7.3 \\
\hline Politiken (broadsheet) & 5.0 & 7.0 \\
\hline Weekly magazines & $\mathbf{1 . 7}$ & $\mathbf{1 . 2}$ \\
\hline Mandag Morgen (political analysis) & 1.3 & .8 \\
\hline Ugebrevet A4 (political analysis) & 0.4 & 0.4 \\
\hline TV stations & $\mathbf{3 2 . 5}$ & $\mathbf{2 3 . 7}$ \\
\hline DR Nyheder (DR news profile) & 4.4 & 8.9 \\
\hline DR2 (TV channel) & 4.6 & 1.4 \\
\hline DR Debatten (political magazine) & 9.4 & 0.4 \\
\hline TV 2 NEWS (news channel) & 2.6 & 9.8 \\
\hline TV 2 Politik (TV 2 political profile) & 10.2 & 2.9 \\
\hline TV 2 Udland (TV 2 foreign profile news) & 1.3 & .3 \\
\hline Radio stations & $\mathbf{2 3 . 7}$ & $\mathbf{4 . 6}$ \\
\hline DR P1 & 4.2 & 3.1 \\
\hline DR P3 & 17.6 & .6 \\
\hline Radio24syv (commercial, public service) & 1.9 & .9 \\
\hline Web media & $\mathbf{1 0 . 8}$ & $\mathbf{1 7 . 1}$ \\
\hline Altinget (political analysis) & 2.2 & 1.2 \\
\hline Dagens.dk (online tabloid) & 3.1 & 8.8 \\
\hline Den Korte Avis (right-wing) & 1.3 & 5.5 \\
\hline Politiko (online political magazine) & 4.2 & 1.6 \\
\hline N & $\mathbf{7 3 3 3 7}$ & $\mathbf{1 5 9 9 9}$ \\
\hline & & \\
\hline
\end{tabular}

Table 2. Comparison of Twitter accounts and Facebook posts for the 25 media. The figures show the relative percentage of all tweets or posts.

Among the TV pages and profiles the picture is more blurred. Twitter profiles belonging to specific shows or programs are more active than their Facebook counterparts. Often there is lively tweeting, for instance during a televised debate in "DR Debatten", accounting for 1 of ten of all tweets. On the other hand, TV 2 is also very active on Twitter with their profile "TV 2 Politik", a general station profile for political news. The Facebook page of TV 2 News is much more active than its Twitter twin. The chan- 
nel uses Facebook mainly for linking and click-baiting to news stories on the screen or on their website.

The biggest difference between Facebook and Twitter is found among the radio stations. DR P3 - the popular music and talk radio channel of public-service provider DR -accounts for 17,6 percent of all tweets. Popular radio station hosts use Twitter excessively to promote their programs and generate response from their listeners.

The web media in this analysis are three political online magazines and Dagens.dk - an online portal for gossip, entertainment and "lighter news". Especially the latter is active on Facebook, generating most of their page views through Facebook stories. Also Den Korte Avis - a right-wing online journal - is most active on Facebook, posting emotional or sensational stories on immigration consequences. Politiko and Altinget - regarded as more balanced and "serious" web sites - are most active on Twitter, however. Finally, the two weekly magazines show almost no activity. A third weekly was excluded from the final sample because it had no Twitter activity at all. The conclusion may be that weeklies have problems sustaining the momentum throughout the week in the constant flux of news on social media.

The activity is relatively even over time with small drops in most weekends. However, there are two noticeable exceptions: the terrorist attack on the French satirical magazine Charlie Hebdo generated increased media activity on Twitter as well as Facebook on the days of attack, January $7^{\text {th }}$ and after. The top activity, however, occurred on February $14^{\text {th }}$ and $15^{\text {th }}$, the days of the terrorist attacks in Copenhagen targeting a meeting featuring Swedish artist Lars Vilks and the Jewish Synagogue in central Copenhagen. The two events spurred a large number of tweets, posts and activity in general. Especially TV 2 News had high Twitter activity and mentions as they were the first to break the story. Another interesting feature is an increase in the number of different locations of the tweets, including many abroad. In other words: Danish media news reached an international audience.

A reading of the posts and tweets from the two events show some differences; Facebook stories often have a personal or more emotional angle whereas Twitter stories are short, reporting and often contains no more than a link to a web story, followed by a 
short description. Such differences might account for different strategies from media but can also be explained by a different format: Tweets are short and invite to factual notifications rather than longer stories adding details and negotiating emotions.

\section{The analysis part II - news criteria of Twitter and Facebook}

I will start by looking at what I call the dominant news criteria across tweets and posts, shown in table 3. In general, fewer tweets than posts have been possible to code, given that they are shorter and there is less text to clearly identify the criteria.

\begin{tabular}{|l|l|l|l|l|l|l|}
\hline & Timeliness & Relevance & Identification & Conflict & Sensation & N \\
\hline Facebook & $22.3 \%$ & $12.5 \%$ & $43.1 \%$ & $11.5 \%$ & $10.6 \%$ & 2913 \\
\hline Twitter & $28.0 \%$ & $14.1 \%$ & $41.7 \%$ & $11.9 \%$ & $4.2 \%$ & 2411 \\
\hline
\end{tabular}

Table 3. Dominant news criteria on Facebook and Twitter.

The difference of dominant news criteria between Facebook and Twitter is statistically significant at a 99 percent level. The timeliness criterion is clearly more identified on Twitter than on Facebook where the posts on the other hand tend to be more "sensational". Differences are not large for relevance, identification and conflict. Timeliness and relevance make the real difference.

We get a more detailed analysis by looking at all news criteria identified in the posts and tweets. The results are shown in table 4.

\begin{tabular}{|l|l|l|l|}
\hline & Facebook & Twitter & N \\
\hline Timeliness * & $\mathbf{5 8 . 4}$ & 44.9 & 3100 \\
\hline Relevance & 19.0 & 17.9 & 1105 \\
\hline Identification * & $\mathbf{6 1 . 9}$ & 45.5 & 3223 \\
\hline Conflict * & $\mathbf{1 5 . 8}$ & 13.1 & 866 \\
\hline Sensation * & $\mathbf{1 5 . 9}$ & 5.5 & 641 \\
\hline N & 3000 & 3000 & \\
\hline
\end{tabular}

Table 4. All news criteria identified in posts and tweets.

Significant differences between Facebook and Twitter marked by an * 
This analysis looks a bit different. Each post or tweet has been coded for each of the criteria, as dummy variables. Therefore, it makes no sense to define $\mathrm{N}$ for each of the platforms. Rather, $\mathrm{N}$ is identified for each category, adding the bonus that we can see the distribution of news criteria in total as well.

The main conclusion of the table is that there are significant differences between Facebook and Twitter for all criteria, except "relevance" and that these differences are larger than when coded for only the dominant news criteria. Expanding the analysis thus makes the difference between Facebook and Twitter more visible. On Facebook posts I can identify more timeliness, sensation and conflict than in tweets. This supports hypotheses from the discussed literature that Facebook stories are more personal, emotional and focused on the spectacular than tweets. Thus it seems as if the media use the platforms for different kinds of stories and different angles. Looking at the figures, it is important to remember that Facebook posts in general contain more criteria than tweets, due to their length and character, as discussed above. This explains why Facebook posts have a higher percentage figure across all criteria.

Bearing this in mind, we can take a look at the general trends in social media framing of news stories. On Facebook as well as Twitter, identification is the most used news criterion, followed by timeliness. Then we have relevance, conflict and sensation but they are less frequently used. Thus, social media stories are often framed by personal angles, calling for the identification of the reader. As such this part of the analysis has a mixed conclusion: The emotional and sensational both play a large role in the social media but not at the expense of the established criteria of timeliness and relevance.

\section{Conclusion}

This study has identified differences in Danish media use of Facebook and Twitter, focusing on overall activity and news criteria. It was expected that the two social media platforms might be used differently, given their different format, architecture and affordances. 
Regarding overall activity, print and web media use Facebook relatively more than Twitter whereas the opposite is the case for radio and TV media. Facebook is often used for framing stories with personal angles, aiming at user identification or communicating emotions. On the other hand, tweets are often shorter, more factual and provide its users with links to stories and an invitation to read more.

There are clear differences between Facebook and Twitter in terms of news criteria. Identification, followed by timeliness, are the two most frequently identified dominant news criteria on both platforms. Relevance is identified evenly on both platforms whereas sensation and conflict are clearly more frequently identified on Facebook. This contributes to an understanding of Twitter as a medium used primarily for facts and reporting whereas Facebook is used for framing of the spectacular or appealing to emotions. On both platforms, however, the media frequently use identification as an indication of the more personal nature of news distributed through social media.

Looking at all criteria identified in the data, a higher average number of criteria are identified in Facebook posts than in tweets, given the longer format and its room for different topics and angles. Considering these structural differences, the tendencies described above are confirmed. Facebook is the more sensational and conflictual, Twitter the more factual medium with more focus on importance as defined in the news criteria.

Some of the differences can be ascribed to the different architecture of the two social media platforms. Tweets are shorter with no space for emotions. In terms of users and activity, Facebook is much more popular than Twitter and the media use their Facebook pages to build communities, as discussed in the literature review.

A final word about the methods: As discussed above no method is perfect for the comparison of different social media platforms. The selected method includes much more Twitter activity in the initial data set, but the equal sample sizes eliminate that difference.

In sum, this study shows that social media are no coherent juggernaut when it comes to news dissemination. Different platforms are used differently, based on their affordances and the 
audience. Twitter is used mainly for short reporting or linking to media stories whereas Facebook posts often seek to engage, invoke emotions or employ personal angles, aiming at user identification. However, the identification criterion is also widely found on Twitter. It is fair to conclude that identification is the main news criterion on both social media platforms. However, pessimistic claims that timeliness and relevance give way for sensation and conflict are not fully confirmed.

One remaining question is whether the media use different strategies deliberately for branding and audience purposes, as some earlier research indicates, or because they believe that the users of the two platforms are different; that Twitter users may prefer quicker, more factual information whereas Facebook is more a "community" medium where people identify with the stories and where emotions are communicated to a larger extent. This question ought to be explored in further studies.

\section{NOTES}

1 The research in this article is part of the project "Meaning Across Media" investigating how media content travels across platforms. The project was sponsored by The Danish National Research Council for Communication and Culture.

The author would like to thank research assistant Mia Thylkjær for coding the dataset and valuable feedback on the data material.

\section{REFERENCES}

Anderson, M, and Caumont, A (2014). "How Social Media is Reshaping News." Pew Research Center.

Asmussen, K and Meilby, M (1977). Før deadline - dagbladsjournalistikkens grundtrin. Copenhagen: Institut for Presseforskning.

Boczkowski, P J \& Mitchelstein, E (2012). How users take advantage of different forms of interactivity on online news sites: Clicking, E Mailing, and commenting. Human Communication Research, 38(1), pp. $1-22$.

Bossetta, M., Segesten, A. D., \& Trenz, H. J. (2017). Engaging with European politics through Twitter and Facebook: Participation beyond the national?. In Social Media and European Politics (pp. 53-76). Palgrave Macmillan, London. 
Bruns, A, Burgess, J, Highfield, T, Kirchhoff, L, \& Nicolai, T (2011). Mapping the Australian networked public sphere. Social Science Computer Review, 29(3), pp. 277-287.

Ekman, M., \&Widholm, A. (2014). Twitter and the celebritisation of politics. Celebrity Studies, 5(4), pp. 518-520.

Epstein, E J (1973). News from Nowhere. New York: Random House.

Galtung, J \& Ruge, M H (1965). The Structure of Foreign News: The Presentation of the Congo, Cuba and Cyprus Crises in Four Norwegian Newspapers. Journal of peace research, 2(1), pp. 64-90.

Gans, H J (1979). Deciding what's news: A study of CBS evening news, NBC nightly news, Newsweek, and Time. Northwestern University Press.

Gleason, S. (2010). Harnessing social media: News outlets are assigning staffers to focus on networking. American Journalism Review, 32(1), pp. 6-8.

Hamdy, N \& Gomaa, E H (2012). Framing the Egyptian uprising in Arabic language newspapers and social media. Journal of Communication, 62(2), pp. 195-211.

Harcup, T \& O'neill, D (2001). What is news? Galtung and Ruge revisited. Journalism studies, 2(2), pp. 261-280.

Harcup T and O'Neill, D (2016). What is news? News values revisited (again). Journalism Studies (1), pp. 1-19.

Hartley, J M (2013). The online journalist between ideals and audiences. Journalism Practice, 7(5), pp. 572-587.

Highfield, T. (2017). Social media and everyday politics. John Wiley \& Sons.

Hille, S., \& Bakker, P. (2013). I like news. Searching for the 'Holy Grail'of social media: The use of Facebook by Dutch news media and their audiences. European Journal of Communication, 28(6), pp. 663-680.

Hjarvard, Stig (1995). Internationale TV-nyheder. København: Akademisk Forlag.

Kalsnes, B \& Larsson, A O (2017). Understanding News Sharing Across Social Media: Detailing distribution on Facebook and Twitter. Journalism Studies, pp. 1-20.

Kilgo, D K., Harlow, S, García-Perdomo, V, \& Salaverría, R (2016). A new sensation? An international exploration of sensationalism and social media recommendations in online news publications. Journalism, 1464884916683549.

Kramhøft, P (2000). Journalistik med omtanke: arbejdsmetoder $i$ udredende og analytisk journalistik. Aarhus: Forlaget Ajour. 
Larsson, A O, \& Christensen, C (2017). From showroom to chat room: SVT on social media during the 2014 Swedish elections. Convergence, 23(6), pp. 587-602.

Linaa Jensen (2017). Same, same - but different: Udfordringer og muligheder ved at studere og sammenligne Facebook og Twitter. In K. Drotner \& S. M. Iversen (eds.). Digitale metoder. Copenhagen: Samfundslitteratur.

Ryan, C (1991). Prime Time Activism: Media Strategies for Grassroots Organizing. Boston: South End Press.

Schrøder, K, Blach-Ørsten, M \& Eberholst, M K (2018). Danskernes brug af nyhedsmedier. Zenodo. http://doi.org/10.5281/zenodo

Schudson, M (1989). The sociology of news production. Media, Culture \& Society, 11(3), pp. 263-282.

Schultz, I (2006). Bag nyhederne - voerdier, idealer og praksis. Copenhagen: Samfundslitteratur.

Schultz, I (2007). The journalistic gut feeling: Journalistic doxa, news habitus and orthodox news values. Journalism practice, 1(2), pp. 190207.

\section{AUTHOR}

Jakob Linaa Jensen

Research Director of Social Media, Danish School of Media and Journalism, Center for Internet Studies, Aarhus University

jlj@dmjx.dk 